\title{
ТЕОРЕТИЧЕСКИЕ ВОПРОСЫ ВИДОВ ГРАЖДАНСКОГО СУДОПРОИЗВОДСТВА
}

\author{
T.C. TAPAHOBA
}

доктор юридических наук, профессор, заведующая кафедрой гражданско-правовых дисциплин факультета права учреждения образования «Белорусский государственный экономический университет»

\begin{abstract}
Аннотация
Проблеме видов производства в юридической литературе в последнее время стало уделяться много внимания, но многие вопросы остаются дискуссионными и нераскрытым в силу их многоаспектности и сложности. На основе анализа существующих в науке точек зрения и законодательства, автор делает собственные выводы по рассматриваемой проблематике.
\end{abstract}

Ключевые слова: виды производства, суд первой инстанции, гражданское судопроизводство

Abstract

To problem of types of proceeding it is paid much attention in legal literature, but many questions remain debatable and unsolved because of its variety and complexity. On the basis of the analysis of the points of view existing in science as well as the legislation, the author draws own conclusions on a considered problematic.

Key words: kinds of proceedings, court of the first instance, civil procedure

\section{ВВЕДЕНИЕ}

В целях доступности правосудия, повышения его эффективности и быстроты, гражданская процессуальная форма может предусматривать процессуальные особенности действия механизма судебной защиты прав и охраняемых законом интересов участников правоотношений.

Гражданская процессуальная форма в целом регламентирует порядок защиты прав и законных интересов юридически заинтересованных в исходе дела лиц в процессе рассмотрения и разрешения гражданских дел, обжалования и пересмотра вынесенных судебных постановлений, а также исполнения судебных и иных постановлений, подлежащих исполнению в гражданском судопроизводстве. Процессуальная форма характеризует форму отправления правосудия в соответствующем виде судопроизводства - гражданском, административном, уголовном, конституционном [1].

В отличие от гражданской процессуальной формы вид производства регулирует обособленную часть правоотношений, особенности которых позволяют применять дифференциацию в сфере гражданского судопроизводства. Под видом гражданского судопроизводства можно понимать процессуальный порядок рассмотрения и разрешения в суде первой инстанции гражданских дел, основанный на универсальности процессуальных правил 
общего характера, применяемых в исковом производстве, а также возможности применения иных процессуальных правил, индивидуализирующих процессуальный порядок рассмотрения и разрешения дел при наличии особенностей правовой природы правоотношений, составляющих предмет судебного разбирательства в отдельных производствах.

\section{РЕЗУЛЬТАТЫ И ИХ ОБСУЖДЕНИЕ}

В гражданском судопроизводстве выделяется несколько видов производства, в которых может осуществляться рассмотрение дел в суде первой инстанции.

Согласно ст. 8 Гражданского процессуального кодекса Республики Беларусь 1999 г. [2] непосредственно выделяется исковое, особое, приказное производство, а также производство по делам, возникающим из административно-правовых отношений.

Традиционно преимущество признается за исковым производством, по правилам которого практически может быть рассмотрено любое гражданское дело. Специальные процессуальные правила, дополняемые правилами искового производства, образуют определенную процедуру рассмотрения в суде дел, формируя таким образом отдельный вид производства. Анализ содержания ст. 8 ГПК свидетельствует, что законодатель не ограничивает перечень видов производства по гражданским делам и указывает на иные виды производства, предусмотренные ГПК и другими законодательными актами.

Вопросы об иных видах производства в законодательстве остался не урегулированным. Возникают вопросы о том, можно ли относить к иному производству правила о рассмотрении дел с участием иностранных лиц, правила об исполнении в Республике Беларусь судами решений иностранных судов и арбитражей (третейских судов), о рассмотрении жалоб (протестов) на действия (бездействие) судебного исполнителя, и на постановления судебного исполнителя.

На взгляд автора, не вполне последовательно при структурировании видов производства учитываются особенности определенных категорий дел. Например, в рамках особого производства рассматриваются дела, имеющие особенности, которые отличаются от традиционных подходов к выделению особого производства.

Речь, в частности, идет о рассматриваемых в порядке особого производства делах о помещении несовершеннолетних в специальные учебно-воспитательные или лечебновоспитательные учреждения, о переводе несовершеннолетних в другие специальные учебновоспитательные или лечебно-воспитательные учреждения, о прекращении пребывания несовершеннолетних в указанных учреждениях до истечения установленного судом срока пребывания, о продлении этого срока, а также о помещении несовершеннолетних в приемникираспределители для несовершеннолетних, о продлении срока нахождения несовершеннолетних в приемниках-распределителях для несовершеннолетних, об освобождении несовершеннолетних из приемников-распределителей для несовершеннолетних. 
Очевидно, что данные дела выходят за общепринятые рамки особого производства, в котором должны устанавливаться факты, имея существенные особенности в порядке возбуждения, рассмотрения и разрешения дел, исполнения судебных постановлений.

По делам данной категории заявление в суд направляется лицом, не имеющим притязаний на предмет рассмотрения и которое не выступает в интересах другого лица. Так, заявление о помещении несовершеннолетних, не подлежащих уголовной ответственности, в специальные учебно-воспитательные и лечебно-воспитательные учреждения, вправе направлять в суд комиссии по делам несовершеннолетних. Заявление о помещении несовершеннолетнего в приемникраспределитель для несовершеннолетних подается начальником органа внутренних дел или его заместителем (ст. 27 Закона Республики Беларусь «Об основах системы профилактики безнадзорности и правонарушений несовершеннолетних» [3], ст. 393-6 ГПК).

Четко определяется не только заявитель, но и перечень прилагаемых к заявлению необходимых документов. К заявлению должны быть приложены документы, предусмотренные законодательством: характеристики с мест учебы (работы) несовершеннолетних; акты обследования семейно-бытовых условий жизни несовершеннолетних; справки органов внутренних дел, содержащие сведения о правонарушениях, ранее совершенных несовершеннолетними, и принятых в связи с этим мерах воздействия; заключения государственных организаций здравоохранения о состоянии здоровья несовершеннолетних и возможности их помещения в специальные учебно-воспитательные учреждения или необходимости их помещения в специальные лечебно-воспитательные учреждения.

Специфика данной категории дел, отличающая от иных дел особого производства, связана и с тем, что по делам о помещении несовершеннолетних в приемники-распределители для несовершеннолетних, о продлении срока нахождения несовершеннолетнего в приемникераспределителе для несовершеннолетних или об освобождении несовершеннолетнего из приемника-распределителя для несовершеннолетних судом выносится не решение, а определение. Такое определение суда подлежит немедленному исполнению.

Исполнение решений возлагается не на службу судебных исполнителей. Согласно ст. 30 Закона Республики Беларусь «Об основах системы профилактики безнадзорности и правонарушений несовершеннолетних» исполнение решений суда о помещении несовершеннолетних, не подлежащих уголовной ответственности, в специальные учебновоспитательные или лечебно-воспитательные учреждения обеспечивают: инспекции по делам несовершеннолетних - в части доставления несовершеннолетних в приемники-распределители для несовершеннолетних; приемники-распределители для несовершеннолетних - в части доставления несовершеннолетних в специальные учебно-воспитательные учреждения или специальные лечебно-воспитательные учреждения; Министерство образования Республики Беларусь - в части предоставления путевок для направления несовершеннолетних в специальные учебновоспитательные учреждения или специальные лечебно-воспитательные учреждения; 
руководители специальных учебно-воспитательных учреждений, специальных лечебновоспитательных учреждений - в части создания и реализации специальных условий воспитания.

Существенные особенности производства, не характерные для рассмотрения и разрешения дел особого производства присущи также делам о направлении гражданина в лечебно-трудовые профилактории, продлении срока нахождения гражданина в лечебно-трудовом профилактории, прекращении нахождения гражданина в лечебно-трудовом профилактории (ст. 393-9-393-12 ГПК).

Рассматривая разделение судопроизводства на виды производств как явление уже существующее, в развитии которого наблюдаются разные подходы, следует остановиться на вопросе о критериях дифференциации гражданского судопроизводства на отдельные виды производства. В основу такой дифференциации могут быть положены критерии процессуальноправового и материально-правового характера.

Материально-правовые критерии включают предмет разбирательства: наличие спора о праве или иной конфликтной ситуации, требующей судебного вмешательства и применения норм материального права. Исходя из материально-правового критерия, выделяются исковые и неисковые виды производства. При этом предметом судебного разбирательства в неисковых производствах является конфликтная ситуация, в связи с которой заинтересованное лицо вынуждено обратиться за судебной защитой своих законных интересов. В юридической литературе указывается, что неисковые производства можно рассматривать как процедуры, имеющие признаки упрощенного процесса по сравнению с исковым производством [4].

Нужно отметить дискуссионность вопроса о выделении видов производств. Г. Добровольский и другие ученые выделяли лишь два самостоятельных вида производства: исковое и особое, полагая, что производство по делам из публичных правоотношений представляет собой разновидность искового производства. Д.М. Чечот, выделяя виды производства, условно подразделял их на «исковые» и «неисковые», понимая под последними производство по делам из административных правоотношений и особое производство. Иная позиция была изложена А.Т. Боннером, который полагал, что правосудие осуществляется только по делам искового производства. Рассмотрение большинства дел особого производства не является осуществлением правосудия, так как в таких случаях суд не рассматривает спор о праве и не применяет норм права $[5]$.

M.Х. Хутыз высказывает свою позицию о видах производств в контексте соотношения с производством в суде первой инстанции. Данный автор полагает, что определение искового производства и неискового производства как видов нарушает логическую схему «род и виды», поскольку неизвестным остается, в чем же состоит родовое понятие, охватывающее виды. М.Х. Хутыз считает, что общие правила производства охватывают исковое производство, в то время как изъятия из общих правил производства предназначаются для дел, возникающих из административно-правовых отношений и дел особого производства [6]. Соглашаясь с такой позицией, можно уточнить, что правила, применяемые в производствах, не являющихся 
исковыми, носят не только характер изъятия, но также конкретизируют и дополняют правила искового производства (например, обязывают выносить решение с мотивировочной частью по определенным категориям дел, возникающим из административно-правовых отношений и делам особого производства).

Критерий процессуально-правового характера определяет дифференциацию производства в зависимости от цели судебного производства (рассмотрение заявленных требований по существу, проверка судом законности и обоснованности действий (бездействий) государственных органов, должностных лиц, установление наличия оснований для отмены решения третейского суда и др.), особенности распределения бремени доказывания, проявления принципов гражданского процесса.

Заслуживает внимания классификация видов производства, предложенная Е.И. Носыревой, на основе признака наличия определенного процессуального порядка. При этом процессуальный порядок определяется как установленная законом последовательность процессуальных действий по рассмотрению судом первой инстанции той или иной совокупности гражданских дел. Е.И. Носырева предлагает классификацию видов гражданского судопроизводства на две большие группы: 1) производства, связанные с рассмотрением дела по существу, куда она относит исковое, особое, приказное и производство, по делам, возникающих из публичных правоотношений); 2) производства не связанные с рассмотрением дела по существу (об оспаривании решений третейских судов и о выдаче исполнительных листов на принудительное исполнение решений третейских судов и производство по делам о признании и привидении в исполнение решений иностранных судов и иностранных арбитражных решений) [7].

Воспользовавшись вышеприведенной классификацией производств, можно указать, что с учетом критерия процессуально-правового характера исковое производство включает более узкие виды, имеющие набор особенностей, предусмотренных законодательством и позволяющие выделить в качестве подвидов, которые обладают общими признаками вида, но имеют существенные отличия по определенным вопросам.

К подвиду искового можно отнести приказное производство, которое отличается от искового производства наличием специфических отличительных признаков и особенностями процессуальных правоотношений.

Нужно указать, что имеются и другие мнения по поводу приказного производства, как вида. Е.И. Носырева относит приказное производство к самостоятельному виду. В иных случаях приказное производство понимается как упрощенная форма защиты прав и законных интересов [8], как подвид искового производства [9], как самостоятельный вид производства [10]. В постановлении Пленума Верховного Суда Республики Беларусь от 29 июня 2006 г. № 4 «О практике рассмотрения судами заявлений в порядке приказного производства» указано, что приказное производство является самостоятельным видом гражданского судопроизводства (п. 1 постановления) [11].

Но даже при дискуссионности мнения о самостоятельности приказного производства можно сделать вывод о том, что приказное производство объединяет с исковым их главный признак - 
наличие спора о праве. Приказное производство можно рассматривать в качестве подвида в рамках искового производства с учетом его следующих особенностей:

- применяется различное наименование сторон, которые в отличие от истца и ответчика в исковом производстве именуются как взыскатель и должник;

- имеются различия в форме обращения заинтересованного лица в суд - с заявлением о возбуждении приказного производства, и с исковым заявлением - в исковом производстве;

- рассмотрение заявленных требований по сравнению с исковым производством имеет упрощенный характер (не требуется подготовки дела к судебному разбирательству и его проведение, вынесение определений, обязательных в исковом производстве: о возбуждении дела и др.);

- ограничено применение принципов состязательности (поскольку стороны не присутствуют в судебном заседании), диспозитивности (не реализуется право на мировое соглашение, возражение на иск, признание иска), гласности (публика не присутствует при рассмотрении требований судом);

- отсутствует необходимость фиксации процедуры рассмотрения и установленных обстоятельств в протоколе судебного заседания;

- в приказном производстве до вынесения определения о судебном приказе применяется представление доказательств суду только взыскателем и только в письменной форме;

- не требуется вынесение судебного решения;

- определен специальный порядок обжалования определения о судебном приказе.

Также к существенным основаниям выделения приказного производства в качестве подвида является то, что в этом виде производства рассматривается специально очерченный круг требований, определенный в ст. ст. 394 ГПК. В п. 1 постановления Пленума Верховного Суда Республики Беларусь от 29 июня 2006 г. № 4 «О практике рассмотрения судами заявлений в порядке приказного производства» разъяснено, что перечень требований, установленный ст. 394 ГПК, которые могут рассматриваться в порядке приказного производства, является исчерпывающим и расширительному толкованию не подлежит.

Относительно недавно гражданское судопроизводство дополнилось заочным производством, которое предоставляет возможность рассматривать в суде дело ex parte - в отсутствие стороны при рассмотрении дела.

Заочное производство может применяться только по гражданским делам, подлежащим рассмотрению в исковом порядке (п. 1 постановления Пленума Верховного Суда Республики Беларусь от 21 декабря 2012 г. № 9 «О практике рассмотрения судами дел в порядке заочного производства» [12]).

Вопрос о видовой принадлежности заочного производства дискуссионный. По мнению Д.М. Чечота, понятие «производство» применительно к заочному производству не несет какой-либо материально-правовой специфики, поэтому не составляет вида производства [13]. Заочное производство не относят к подвидам, поскольку его применяют в исключительных случаях 
(неявка ответчика в судебное заседание) и при наличии указанных в законе условий, нежели при нормальном ходе судебного процесса [14].

Предмет разбирательства в заочном производстве остается идентичным исковому производству. Вместе с тем на взгляд автора статьи, заочное производство может рассматриваться в качестве подвида искового производства, имеющего при этом важное значение для защиты прав истца в случае, когда ответчик уклоняется от явки в суд, в целях обеспечения соблюдения сроков рассмотрения гражданских дел, сокращения процессуальных издержек.

Заочное производство может быть выделено в качестве подвида на основе критерия процессуально-правового характера. Данный вывод основывается на том, что применение заочного производства возможно только при наличии определенных условий и особенностей, имеющих существенное значение для складывающихся процессуальных правоотношений.

Условия, при которых возможно рассмотрение спора в заочном производстве образуют совокупность значимых условий, включая:

- неявку ответчика без уважительных причин, а если в деле участвуют несколько ответчиков - то неявку без уважительных причин всех ответчиков по делу, либо если суд признает, что надлежаще извещенный ответчик (ответчики) умышленно затягивает производство по делу. При этом ответчик (ответчики) должен быть надлежаще извещен о времени и месте судебного заседания;

- должно быть известно место фактического пребывания ответчика. Не допускается применение правил заочного производства при неизвестности фактического места пребывания ответчика, в том числе и при розыске ответчика;

- наличие согласия истца на рассмотрение дела в исковом производстве, а при участии в деле третьих лиц, заявляющих самостоятельные требования на предмет спора, их согласие на рассмотрение дела в порядке заочного производства также является обязательным;

- неизменность предмета, основания иска, увеличения размера исковых требований. В случае изменения истцом предмета или основания иска, увеличения размера исковых требований суд не вправе рассматривать дело в этом судебном заседании в порядке заочного производства. Только после надлежащего уведомления ответчика об изменении предмета или основания иска, увеличении размера исковых требований дело может быть рассмотрено в заочном производстве (п. 4 постановления Пленума Верховного Суда Республики Беларусь от 21 декабря 2012 г. № 9 «О практике рассмотрения судами дел в порядке заочного производства»).

Помимо условий, специфика подвида заочного производства обусловлена рядом особенностей, имеющих отличительный характер, которые состоят в том, что:

- рассмотрение дела в заочном производстве проводится с учетом доказательств, имеющихся в деле и представленных истцом в судебном заседании;

- по результатам рассмотрения дела выносится решение, имеющее специальное название «заочное решение», в котором описательная часть может не содержать сведения о правовой позиции ответчика. В резолютивной части заочного решения, кроме срока и порядка 
кассационного обжалования, должны указываться срок и порядок подачи ответчиком заявления об отмене заочного решения;

- законодательством предусматривается специальный порядок пересмотра заочного решения, которое может быть отменено тем же судом, который его вынес;

- подавать заявление об отмене заочного решения может только ответчик и такое право не предоставляется истцу либо иным юридически заинтересованным в исходе дела лицам;

- специфика заочного решения, а вслед за этим и заочного производства, в котором такое решение вынесено, проявляется и в том, что основанием к отмене заочного решения суда является наличие уважительных причин неявки в судебное заседание ответчика, о которых он не мог своевременно сообщить суду, и представление им доказательств, которые могут повлиять на содержание решения суда, либо заявление ходатайства об истребовании таких доказательств, если их представление для него невозможно (п.13 постановления Пленума Верховного Суда Республики Беларусь от 21 декабря 2012 г. № 9 «О практике рассмотрения судами дел в порядке заочного производства»).

\section{ВЫВОДЫ}

Подводя итог проведенному анализу, можно сделать вывод о том, что эффективность гражданского судопроизводства во многом зависит от возможностей рассмотрения гражданских дел в оптимальных процессуальных формах, предусматривающих предоставление дополнительных гарантий участникам гражданского судопроизводства, упрощение порядка и сокращение сроков рассмотрения дел отдельных категорий. Это обусловливает необходимость дальнейшей разработки проблем видов производства, позволяющих определять направления дифференциации гражданского судопроизводства, создание новых процессуальных конструкций в данной сфере и их закрепление в законодательстве.

\section{ЛИТЕРАТУРА}

1. Дегтярев, С.Л. Реализация судебной власти в гражданском судопроизводстве: теоретико-прикладные проблемы / С.Л.Дегтярев. - М.: Волтерс Клувер, 2007. - 376 с. - С. 11.

2. Гражданский процессуальный кодекс Республики Беларусь: Кодекс Республики Беларусь от 11.01.1999 N 238-3 // Нац. реестр правовых актов Респ. Беларусь. - 1999. - № 18-19. $2 / 13$.

3. Об основах системы профилактики безнадзорности и правонарушений несовершеннолетних: Закон Республики Беларусь от 31.05.2003 N 200-3 // Нац. реестр правовых актов Респ. Беларусь.. - 2003. - № 64. - 2/949.

4. Селиванов, А.С. К обсуждению вопроса об упрощении гражданского процесса по отдельным делам рассматриваемым по правилам главы 25 ГК РФ \А.С. Селиванов // Арбитражный и гражданский процесс. - 2013. - № 5. - С. 59-62. - С. 60. 
5. Чудиновская, Н.А. Установление юридических фактов в особом производстве гражданского и арбитражного процесса: общее и особенное (некоторые аспекты) \ Арбитражный и гражданский процесс. - 2005.- № 9. - С. 15-19. - С. 16.

6. Х Хутыз, М.Х. Общие положения гражданского процесса: историко-правовое исслед. / М.Х. Хутыз. - М.: Юрид. лит., 1979. - 109 с. - С. 25-27.

7. Носырева Е.И. Виды современного гражданского судопроизводства и их классификация // Заметки о современном гражданском и арбитражном процессуальном праве / Под ред. М.К.Треушникова. — М.: ОАО «Издат. дом «Городец», 2004. — 352 с. - С. 93-96.

8. Коршунов, Н.М. Гражданский процесс: учеб. для вузов / Н.М. Коршунов, Ю.Л.Мареев. - М: Норма, 2006. - 848 с. - С. 176.

9. Фурсов С.Я. Сравнительный анализ гражданских процессуальных кодексов России и Украины // Заметки о современном гражданском и арбитражном процессуальном праве / Под ред. М.К.Треушникова. — М.: ОАО «Издат. дом «Городец», 2004. -352 с. - С. 82.

10. ${ }^{1}$ Тихиня, В.Г. Гражданский процесс: учебник / В.Г.Тихиня. - Минск: Право и экономика, 2004. - 546 с. - С. 36.

11. О практике рассмотрения судами заявлений в порядке приказного производства: постановление Пленума Верховного Суда Республики Беларусь, 19 июня 2006 г. № 4 \\ Нац. реестр правовых актов Респ. Беларусь. - 2006. - № 109. - 6/480.

12. О практике рассмотрения судами дел в порядке заочного производства: Постановление Пленума Верховного Суда Республики Беларусь, 21 дек. 2012 г. № 9 \\ Нац. правовой Интернет-портал Респ. Беларусь. -2013. - 6/1270.

13. Гражданский процесс: учебник / А.П. Вершинин [и др.]; под ред. В.А. Мусина, Н.А. Чечиной, Д.М. Чечота. - 2-е изд., перераб. и доп. - М.: Проспект, 1999. - 472 с. - С. 12-13.

14. Зарубина, М.Н. О некоторых вопросах отнесения производства о присуждении компенсации за нарушение права на судопроизводство в разумный срок и права на исполнение судебного постановления в разумный срок к исковому виду гражданского судопроизводства \ М.Н. Зарубина // Арбитражный и гражданский процесс. - 2011. - № 2. - С. 25 - 29. 